\title{
Measuring Energy Efficiency in Kerala: Data Envelopment Analysis
}

\author{
Vijayamohanan Pillai N., AM Narayanan \\ Associate Professor, Centre for Development Studies, Prasanth Nagar, Ulloor, Trivandrum -, Kerala, India \\ Senior Consultant, Energy Management Centre, Srikrishna Nagar, Sreekaryam P.O,, Trivandrum - Kerala, India \\ thusspakevm@gmail.com; narayan@keralaenergy.gov.in
}

\begin{abstract}
Traditionally, there are two basically reciprocal energy efficiency Indicators: one, in terms of energy intensity, that is, energy use per unit of activity output, and the other, in terms of energy productivity, that is, activity output per unit of energy use. The enquiry that has proceeded from the problems associated with this method of a single energy input factor in terms of productivity has led to multi-factor productivity analysis. We have here two approaches: parametric and non-parametric. Parametric approach famously includes two methods: the erstwhile popular total factor energy productivity analysis and the currently fanciful stochastic frontier production function analysis; The non-parametric approach is popularly represented by data envelopment analysis. The present paper is an attempt to measure efficiency in electrical energy consumption in Kerala, India. We apply the non-parametric mathematical programming method of data envelopment analysis of the multi-factor productivity approach, and estimate the efficiency measures under the two scale assumptions of constant returns to scale (CRS) and variable returns to scale (VRS); the latter includes both increasing (IRS) and decreasing returns to scale (DRS). Scale efficiency measures are also given to find out whether a firm is operating at its optimal size or not, implying degrees of capacity utilization.
\end{abstract}

\section{Introduction}

Traditionally, there are two basically reciprocal energy efficiency Indicators: one, in terms of energy intensity, that is, energy use per unit of activity output, and the other, in terms of energy productivity, that is, activity output per unit of energy use. As a general concept, "energy efficiency refers to using less energy to produce the same amount of services or useful output. For example, in the industrial sector, energy efficiency can be measured by the amount of energy required to produce a tonne of product." (Patterson, 1996: 377). Thus Patterson defines energy efficiency broadly by the simple ratio of the useful output of a process in terms of any good produced that is enumerated in market process, to energy input into that process (ibid.).

Energy efficiency research in general has opened up three avenues of enquiry, namely, the measurement of energy productivity, the identification of impact elements and the energy efficiency assessment. The traditional interest in energy efficiency has centred on a single energy input factor in terms of productivity that has become famous through the index method proposed by Patterson (1996). In this case, energy intensity is obtained by 
Vijayamohanan Pillai N., AM Narayanan; Measuring Energy Efficiency in Kerala: Data Envelopment Analysis, Journal of Biomedical Engineering and Medical Imaging, Volume 6, No 4, Aug (2019) , pp 16-28

dividing energy consumption by GDP, which implies the quantum of energy consumption that must be input in order to increase one unit of GDP. The enquiry that has proceeded from the problems associated with this method has led to identifying the effect source of variation, in terms of some decomposition analysis. Analyzed in terms of energy intensity changes, the index falls under two major decomposition methods, namely, Structural Decomposition Analysis (SDA) and Index Decomposition Analysis (IDA).

SDA has both inputs and outputs as its theoretical foundation, and is hence also known as equilibrium analysis. There are two approaches here: input-output method and neo-classical production function method.

The stringent assumptions associated with these approaches have made them practically unattractive for policyorientated empirical exercises. Moreover, the prime significance of energy consumption reduction through energy use efficiency improvements following the 1973 oil crisis has essentially required complete evaluation of energy consumption patterns and identifying the driving factors of changes in energy consumption, creating a demand for effective tools to decompose aggregate indicators.

This need led to the development of the Index Decomposition Analysis (IDA) in the late 1970s in the United States (Myers and Nakamura 1978) and in the United Kingdom (Bossanyi 1979). These pioneering studies then spurred a number of different decomposition methods, most of which were derived from the index number theory, initially developed in economics to study the respective contributions of price and quantity effects to final aggregate consumption. A variant of factor decomposition analysis, IDA takes energy as a single factor of production, and explores various effects on energy intensity changes, by decomposing these changes into pure intensity changes effect and industrial structure changes effect. The first component (pure intensity changes effect) implies that when the industrial structure remains unchanged, the energy intensity change may be taken as the result of energy use efficiency changes in some sector, and the second implies that given the fixed energy efficiencies of various industries and their different energy intensity levels, the total energy intensity changes effect may be taken as the result of the dynamic changes of the yield of each industry.

IDA, as applied to time series data of a specific period, involves results which are very sensitive to the choice of the base period during the study period. In terms of the selection of base period, the approach usually considers Laspeyres Index of fixed weights and Divisia Index of variable weights.

Divisia index decomposition approach has become very popular these days in the context of analysis of energy intensity changes (see Ang and Zhang (2000), and Ang (2004) for a survey of index decomposition analysis in this field). There are two common Divisia index decomposition methods: Arithmetic mean (AMDI) and Logarithmic Mean Divisia index (LMDI). The AMDI method was first used by Gale Boyd, John McDonald, M. Ross and D. A. Hansont in 1987, for "separating the changing composition of the US manufacturing production from energy efficiency improvements" using Divisia index approach (as the title shows). This was followed by a number of studies, some attempts being directed towards modifying the index. These efforts were finally culminated in Ang and Choi (1997), who used logarithmic mean function as weights for aggregation with the attractive property that the decomposition leaves no residuals at all. Ang et al. (1998) called this model "Logarithmic Mean Divisia index (LMDI)".

Finally, a new energy efficiency estimation method, criticizing the single factor energy efficiency method, has come up utilizing a multi-variate structure. We have here two approaches: parametric and non-parametric. Parametric approach famously includes two methods: the erstwhile popular total factor energy productivity 
analysis and the currently fanciful stochastic frontier production function analysis; The non-parametric approach is popularly represented by data envelopment analysis.

In this paper we apply the second approach in multi-factor productivity analysis, that is, the non-parametric mathematical programming method of data envelopment analysis. The paper is structured in four parts. The next section presents the theoretical framework of data envelopment analysis (DEA) as a prelude to our empirical exercise for the Kerala power sector. Part three discusses the DEA results from the empirical study. The last section concludes the chapter.

\section{Data Envelopment Analysis (DEA)}

It was Farrell (1957) who stimulated econometric modeling of production functions as frontiers. He decomposed the concept of economic efficiency (which he called overall efficiency) of a production unit into two components, viz., technical efficiency and allocative efficiency (which he called price efficiency); the former refers to the capability of the unit to produce maximum output from a given bundle of inputs, and the latter to the capability of the unit to utilize the inputs in an optimum proportion subject to the given input prices. He illustrated the concept using isoquant and price line (now called isocost line; these are the basic tools used in economic textbooks) implyng a production function of two inputs ( $\mathrm{X} 1$ and $\mathrm{X} 2$ ) for a single output ( $\mathrm{Y}$ ), under the assumption of constant returns to scale. "'Returns to scale' describes the output response to a proportionate increase of all inputs. If output increases by the same proportion, returns to scale are constant for the range of input combinations under consideration. They are increasing if output increases by a greater proportion and decreasing if it increases by a smaller proportion." (Henderson and Quandt 1971: 79).

An isoquant is "the locus of all combinations of $X 1$ and $X 2$ which yield a specified output level", that is, $Y 0$, which is a parameter. (Henderson and Quandt 1971: 58). An isocost line is "the locus of input combinations that may be purchased for a specified total cost: $C 0=r 1 X 1+r 2$ X2 +b" (Henderson and Quandt 1971: 63), where $r 1$ and the $\mathrm{r} 2$ are the respective prices of the two inputs and $\mathrm{b}$ is the cost of the fixed inputs. The production unit is said to be in equilibrium at $C$, where the isoquant, $I^{\prime}$, is tangential to the price line (PP'). Thus the point $C$ represents an efficient point.

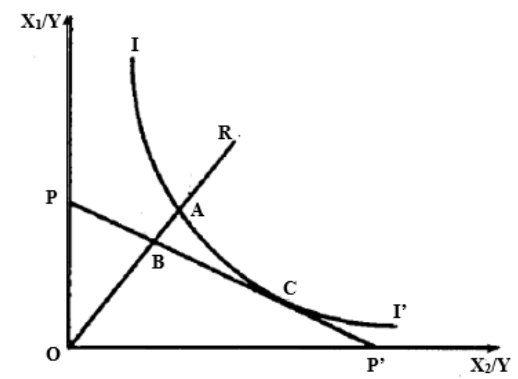

Figure. 1: Farrel's Representation of Technical and Allocative Efficiencies

Note that Farrel used isoquant in a two-input space as an output frontier (maximum output) and hence all the points on the isoquant $\mathrm{II}^{\prime}$ are technically efficient. Thus the points $A$ and $\mathrm{C}$ are both technically efficient, but $\mathrm{R}$ is not. If a production unit is producing at point $R$, its technical inefficiency is given by the distance $A R$, which implies that the unit could proportionally reduce all inputs by this amount without reducing its output. This distance can also be represented in percentage terms by the ratio AR/OR. This allows us to measure the technical efficiency of 
Vijayamohanan Pillai N., AM Narayanan; Measuring Energy Efficiency in Kerala: Data Envelopment Analysis, Journal of Biomedical Engineering and Medical Imaging, Volume 6, No 4, Aug (2019) , pp 16-28

the unit by one minus $A R / O R$, which is equal to the ratio OA/OR. Since this ratio lies between zero and one, it functions as a measure of the degree of technical efficiency of the production unit; a value of one means the unit is technically efficient, and a value close to zero means it is technically inefficient.

We have seen that the points $\mathrm{A}$ and $\mathrm{C}$ are both technically efficient; but there is some difference between them; this is in terms of allocative efficiency. Note that Farrel used price line in a two-input space as a cost frontier (minimum cost) and hence all the points on the price line PP' are allocatively efficient. Thus points $\mathrm{B}$ and $\mathrm{C}$ are both allocatively efficient. But $\mathrm{C}$ is also on the isoquant and hence is also technically efficient; Thus point $\mathrm{C}$ is both technically and allocatively efficient. But point $A$ is only technically efficient, not allocatively.

If the unit is producing at point $R$, its allocative efficiency is given by the ratio $O B / O A$, because the distance $B A$ can be taken as the fall in production costs corresponding to the production at the technically and allocatively efficient point $C$, rather than at the technically efficient, but allocatively inefficient, point $A$. The overall (economic) efficiency is then defined by the ratio $O B / O R$, the distance $B R$ being taken as representing a cost reduction. This economic efficiency measure also is bounded by zero and unity. Also note that the overall (economic) efficiency at point $R$ is obtained from the product of technical and allocative efficiency: $(O A / O R)(O B / O A)=O B / O R$.

As already noted, the efficiency of a production unit is measured in relation to an efficient isoquant (representing an efficient firm), which is in fact unknown and must be estimated using the sample data. For estimation, Farrell suggested (i) a non-parametric piecewise-linear convex isoquant, estimated from the data in such a way that no actual data point should lie to the left or below it, or (ii) a parametric frontier function, such as the Cobb-Douglas production function, estimated from the data in such a way that no actual data point should lie to the right or above it. The second of these we have employed in the last chapter, and the first one we are estimating in this chapter.

Very few researchers were enthused with Farrell's (1957) proposal of the piecewise-linear convex isoquant. Suggestions came up after a while from Boles (1966) and Afriat (1972) to employ mathematical programming methods that also failed in appeal. However, a new model, proposed by Charnes, Cooper and Rhodes (1978) by the name of 'data envelopment analysis (DEA)', immediately caught the fancy of the world and a large number of papers have followed it in applications and extensions. Charnes, Cooper and Rhodes (1978) assumed constant returns to scale (CRS), whereas Banker, Charnes and Cooper (1984) proposed a variable returns to scale (VRS) model. For detailed discussions, see Coelli, Rao, O'Donnell and Battese (2005) and Cooper, Seiford and Tone (2006).

"Data Envelopment Analysis (DEA) was accorded this name because of the way it "envelops" observations in order to identify a "frontier" that is used to evaluate observations representing the performances of all of the entities that are to be evaluated." (Cooper, Seiford and Tone 2006: xix). DEA is a linear programming technique that seeks to optimize an objective function subject to certain inequality constraints. Here the objective function relates to the frontier function of the production unit, called in the DEA literature as decision making unit (DMU). The model seeks to estimate for each DMU an efficiency measure in terms of weighted output-input ratio, which can be written in matrix notation as $a^{\prime} Y^{\prime} / b^{\prime} X i$, where the numerator is a weighted average of all the outputs of the ith DMU and the denominator is its weighted inputs, with $a$ and $b$ being column vectors of output and input weights respectively. Then the linear programming (LP) problem is to choose the optimal weights such as to maximize the efficiency measure (the weighted output-input ratio) subject to the constraints that this measure (ratio) is less than or equal to unity and the weights are non-negative: 


$$
\begin{aligned}
& \operatorname{Max}_{a, b}\left(a^{\prime} Y_{i} / b^{\prime} X_{i}\right), \\
& \text { st } a^{\prime} Y_{i} / b^{\prime} X_{i} \leq 1, \quad i=1,2, \ldots, N, \\
& a, b \geq 0 .
\end{aligned}
$$

However, this formulation has a problem that it would yield an infinite number of solutions. This problem can be averted by adding another constraint that $\beta^{\prime} \mathrm{Xi}=1$. Thus the above LP problem can be reformulated as

$$
\begin{aligned}
& \operatorname{Max}_{\alpha, \beta}\left(\alpha^{\prime} Y_{i} / \beta^{\prime} X_{i}\right), \\
& \text { st } \beta^{\prime} X_{i}=1 \\
& \alpha^{\prime} Y_{i}-\beta^{\prime} X_{i} \leq 0, \quad i=1,2, \ldots, N, \\
& \alpha, \beta \geq 0 .
\end{aligned}
$$

Note that the notations change from $a$ and $b$ to $\alpha$ and $\beta$ to reflect the transformation, which is known as the multiplier form of the LP problem.

We can use the duality in LP to derive an equivalent envelopment form of the multiplier form problem:

minq, I q,

$$
\begin{aligned}
& \text { st }-Y i+y l^{3} 0, \\
& q X i-x l^{3} 0 \\
& I^{3} 0,
\end{aligned}
$$

where $q$ is a scalar representing the efficiency score for the ith DMU that satisfies $q f 1$, and I is a column ( $N \times 1$ ) vector of constants. The advantage of this envelopment form is that it has fewer constraints than the multiplier form, and hence its appeal. A value of $q=1$ means a point on the frontier representing a technically efficient DMU, according to the Farrell (1957) definition.

\section{Data Envelopment Analysis: Empirical Results}

For estimating the DEA frontier of the power sector in Kerala (in India), we consider three sectors as above (Primary, Secondary and Tertiary) for the period from 1970-71 to 2016-17. Because of the data unavailability for estimating the usual output-input relationship, we propose the following relationship:

Sectoral energy consumption $=\mathrm{f}$ (Sectoral number of consumers; Sectoral GSDP at constant 2011-12 prices); all variables in log.

Note that unlike the usual frontier function with factors of production, we have a frontier isoquant with two activity factors and one output.

For estimating DEA, we have made use of a Stata module for DEA, provided by Yong-bae Ji and Choonjoo Lee, (2010).

Tables 1 - 3 report the DEA estimates of efficiency measures for the three sectors under the two scale assumptions of constant returns to scale (CRS) and variable returns to scale (VRS); the latter includes both increasing (IRS) and decreasing returns to scale (DRS). Thus we examine whether the observed performance of the sectors in each year is along the frontier corresponding to a particular returns to scale. Scale efficiency 
Vijayamohanan Pillai N., AM Narayanan; Measuring Energy Efficiency in Kerala: Data Envelopment Analysis, Journal of Biomedical Engineering and Medical Imaging, Volume 6, No 4, Aug (2019) , pp 16-28

measures are also given; scale efficiency denotes whether a firm is operating at its optimal size or not, implying degrees of capacity utilization. If the firm is in underutlization, then using information on increasing or decreasing returns to scale, we can find out whether the firm is too large or too small.

Table 1: DEA Efficiency Estimates - Primary Sector

\begin{tabular}{|c|c|c|c|c|c|c|c|c|c|c|c|}
\hline Year & CRS & VRS & NIRS & Scale & RTS & Year & CRS & VRS & NIRS & Scale & RTS \\
\hline 1970-71 & 0.519 & 0.519 & 1.000 & 0.999 & IRS & 1994-95 & 0.691 & 0.696 & 0.696 & 0.992 & IRS \\
\hline $1971-72$ & 0.595 & 0.596 & 0.970 & 0.998 & IRS & $1995-96$ & 0.712 & 0.717 & 0.717 & 0.994 & IRS \\
\hline $1972-73$ & 0.601 & 0.603 & 0.851 & 0.997 & IRS & 1996-97 & 0.720 & 0.725 & 0.725 & 0.993 & IRS \\
\hline $1973-74$ & 0.622 & 0.624 & 0.798 & 0.996 & IRS & $1997-98$ & 0.728 & 0.731 & 0.731 & 0.996 & IRS \\
\hline $1974-75$ & 0.625 & 0.628 & 0.741 & 0.995 & IRS & 1998-99 & 0.734 & 0.737 & 0.737 & 0.996 & IRS \\
\hline $1975-76$ & 0.635 & 0.638 & 0.701 & 0.994 & IRS & $1999-00$ & 0.754 & 0.757 & 0.757 & 0.996 & IRS \\
\hline $1976-77$ & 0.609 & 0.613 & 0.613 & 0.993 & IRS & $2000-01$ & 0.750 & 0.753 & 0.753 & 0.996 & IRS \\
\hline 1977-78 & 0.581 & 0.585 & 0.585 & 0.993 & IRS & 2001-02 & 0.723 & 0.726 & 0.726 & 0.996 & IRS \\
\hline 1978-79 & 0.588 & 0.593 & 0.593 & 0.993 & IRS & 2002-03 & 0.607 & 0.610 & 0.610 & 0.996 & IRS \\
\hline $1979-80$ & 0.578 & 0.583 & 0.583 & 0.992 & IRS & 2003-04 & 0.624 & 0.626 & 0.626 & 0.996 & IRS \\
\hline $1980-81$ & 0.588 & 0.592 & 0.592 & 0.993 & IRS & 2004-05 & 0.606 & 0.609 & 0.609 & 0.994 & IRS \\
\hline $1981-82$ & 0.604 & 0.607 & 0.607 & 0.995 & IRS & 2005-06 & 0.603 & 0.607 & 0.607 & 0.993 & IRS \\
\hline $1982-83$ & 0.602 & 0.604 & 0.604 & 0.997 & IRS & 2006-07 & 0.624 & 0.626 & 0.626 & 0.996 & IRS \\
\hline $1983-84$ & 0.604 & 0.604 & 0.604 & 0.999 & IRS & 2007-08 & 0.629 & 0.632 & 0.632 & 0.996 & IRS \\
\hline $1984-85$ & 0.588 & 0.589 & 0.589 & 0.999 & IRS & 2008-09 & 0.624 & 0.628 & 0.628 & 0.994 & IRS \\
\hline $1985-86$ & 0.603 & 0.603 & 0.603 & 0.999 & IRS & $2009-10$ & 0.640 & 0.643 & 0.643 & 0.995 & IRS \\
\hline $1986-87$ & 0.648 & 0.649 & 0.649 & 0.999 & IRS & 2010-11 & 0.632 & 0.634 & 0.634 & 0.996 & IRS \\
\hline $1987-88$ & 0.668 & 0.668 & 0.668 & 0.999 & IRS & 2011-12 & 0.655 & 0.658 & 0.658 & 0.996 & IRS \\
\hline 1988-89 & 0.683 & 0.684 & 0.684 & 0.998 & IRS & 2012-13 & 0.664 & 0.667 & 0.667 & 0.996 & IRS \\
\hline $1989-90$ & 0.686 & 0.688 & 0.688 & 0.998 & IRS & 2013-14 & 0.666 & 0.669 & 0.669 & 0.996 & IRS \\
\hline $1990-91$ & 0.671 & 0.673 & 0.673 & 0.997 & IRS & 2014-15 & 0.660 & 0.662 & 0.662 & 0.996 & IRS \\
\hline 1991-92 & 0.678 & 0.679 & 0.679 & 0.997 & IRS & 2015-16 & 0.658 & 0.661 & 0.661 & 0.996 & IRS \\
\hline $1992-93$ & 0.687 & 0.689 & 0.689 & 0.997 & IRS & $2016-17$ & 0.673 & 0.676 & 0.676 & 0.996 & IRS \\
\hline $1993-94$ & 0.694 & 0.698 & 0.698 & 0.995 & IRS & & & & & & \\
\hline
\end{tabular}

Note: CRS = Constant returns to scale; VRS = Variable returns to scale; NIRS = Non-increasing returns to scale; RTS $=$ Returns to scale; Scale $=$ Scale efficiency .

Table 1 shows that energy efficiency in the primary sector is much lower than in the other two sectors; the scale efficiency is below, but close to, optimum. Surprisingly, the sector during the entire period is found to be in IRS stage.

Table 2: DEA Efficiency Estimates - Secondary Sector

\begin{tabular}{|l|l|l|l|l|l|l|l|l|l|l|l|}
\hline Year & CRS & VRS & NIRS & Scale & RTS & Year & CRS & VRS & NIRS & Scale & RTS \\
\hline $1970-71$ & 1.000 & 1.000 & 1.000 & 1.000 & CRS & $1994-95$ & 0.995 & 0.998 & 0.998 & 0.997 & DRS \\
\hline $1971-72$ & 0.988 & 0.988 & 0.988 & 1.000 & IRS & $1995-96$ & 0.997 & 1.000 & 1.000 & 0.997 & DRS \\
\hline
\end{tabular}


Journal of Biomedical Engineming and Medical Imaging, Volume 6, No 4, August 2019

\begin{tabular}{|l|l|l|l|l|l|l|l|l|l|l|l|}
$1972-73$ & 0.993 & 0.994 & 0.994 & 0.999 & DRS & $1996-97$ & 0.948 & 0.950 & 0.950 & 0.997 & IRS \\
\hline $1973-74$ & 0.991 & 0.991 & 0.991 & 1.000 & IRS & $1997-98$ & 0.960 & 0.962 & 0.962 & 0.998 & IRS \\
\hline $1974-75$ & 0.987 & 0.987 & 0.987 & 1.000 & CRS & $1998-99$ & 0.987 & 0.990 & 0.990 & 0.997 & DRS \\
\hline $1975-76$ & 0.989 & 0.989 & 0.989 & 1.000 & CRS & $1999-00$ & 0.988 & 0.991 & 0.991 & 0.997 & DRS \\
\hline $1976-77$ & 0.986 & 0.988 & 0.986 & 0.999 & IRS & $2000-01$ & 0.999 & 1.000 & 1.000 & 0.999 & DRS \\
\hline $1977-78$ & 1.000 & 1.000 & 1.000 & 1.000 & CRS & $2001-02$ & 0.981 & 0.985 & 0.985 & 0.996 & DRS \\
\hline $1978-79$ & 0.998 & 0.998 & 0.998 & 1.000 & IRS & $2002-03$ & 0.973 & 0.979 & 0.979 & 0.994 & DRS \\
\hline $1979-80$ & 0.983 & 0.983 & 0.983 & 1.000 & IRS & $2003-04$ & 0.961 & 0.968 & 0.968 & 0.992 & DRS \\
\hline $1980-81$ & 0.995 & 0.997 & 0.997 & 0.997 & DRS & $2004-05$ & 0.971 & 0.981 & 0.981 & 0.990 & DRS \\
\hline $1981-82$ & 0.985 & 0.986 & 0.986 & 0.999 & IRS & $2005-06$ & 0.973 & 0.984 & 0.984 & 0.989 & DRS \\
\hline $1982-83$ & 0.992 & 0.993 & 0.992 & 0.999 & IRS & $2006-07$ & 0.978 & 0.990 & 0.990 & 0.987 & DRS \\
\hline $1983-84$ & 0.968 & 0.969 & 0.969 & 0.998 & IRS & $2007-08$ & 0.979 & 0.992 & 0.992 & 0.987 & DRS \\
\hline $1984-85$ & 0.994 & 0.995 & 0.995 & 0.999 & DRS & $2008-09$ & 0.976 & 0.988 & 0.988 & 0.988 & DRS \\
\hline $1985-86$ & 1.000 & 1.000 & 1.000 & 1.000 & DRS & $2009-10$ & 0.988 & 1.000 & 1.000 & 0.988 & DRS \\
\hline $1986-87$ & 0.981 & 0.986 & 0.981 & 0.995 & IRS & $2010-11$ & 0.987 & 0.999 & 0.999 & 0.987 & DRS \\
\hline $1987-88$ & 0.963 & 0.968 & 0.963 & 0.996 & IRS & $2011-12$ & 0.985 & 0.998 & 0.998 & 0.987 & DRS \\
\hline $1988-89$ & 0.982 & 0.985 & 0.982 & 0.997 & IRS & $2012-13$ & 0.987 & 1.000 & 1.000 & 0.987 & DRS \\
\hline $1989-90$ & 1.000 & 1.000 & 1.000 & 1.000 & CRS & $2013-14$ & 0.986 & 0.999 & 0.999 & 0.987 & DRS \\
\hline $1990-91$ & 0.997 & 0.997 & 0.997 & 1.000 & IRS & $2014-15$ & 0.987 & 1.000 & 1.000 & 0.987 & DRS \\
\hline $1991-92$ & 1.000 & 1.000 & 1.000 & 1.000 & CRS & $2015-16$ & 0.988 & 1.000 & 1.000 & 0.988 & DRS \\
\hline $1992-93$ & 0.986 & 0.986 & 0.986 & 0.999 & IRS & $2016-17$ & 0.986 & 1.000 & 1.000 & 0.986 & DRS \\
\hline $1993-94$ & 0.986 & 0.988 & 0.988 & 0.998 & DRS & & & & & & \\
\hline
\end{tabular}

Note: $C R S$ = Constant returns to scale; VRS = Variable returns to scale; NIRS = Non-increasing returns to scale; DRS = decreasing returns to scale; RTS = Returns to scale; Scale = Scale efficiency.

However, the story is different for the other two sectors. Table 2 shows that energy efficiency in the secondary sector is the highest for all the years, its performance in a number of years being on or very close to the frontier; so is the scale efficiency also. However, the returns to scale registers a variable pattern: in the initial years, the sector mostly experienced IRS or CRS, whereas from the late 1990s the sector fell in the stage of DRS.

Table 3: DEA Efficiency Estimates - Tertiary Sector

\begin{tabular}{|l|l|l|l|l|l|l|l|l|l|l|l|}
\hline Year & CRS & VRS & NIRS & Scale & RTS & Year & CRS & VRS & NIRS & Scale & RTS \\
\hline $1970-71$ & 0.830 & 0.832 & 0.830 & 0.998 & IRS & $1994-95$ & 0.946 & 0.953 & 0.966 & 0.993 & DRS \\
\hline $1971-72$ & 0.823 & 0.824 & 0.823 & 0.999 & IRS & $1995-96$ & 0.948 & 0.956 & 0.969 & 0.992 & DRS \\
\hline $1972-73$ & 0.737 & 0.737 & 0.737 & 0.999 & IRS & $1996-97$ & 0.961 & 0.969 & 0.982 & 0.992 & DRS \\
\hline $1973-74$ & 0.830 & 0.831 & 0.830 & 0.999 & IRS & $1997-98$ & 0.967 & 0.975 & 0.989 & 0.992 & DRS \\
\hline $1974-75$ & 0.753 & 0.754 & 0.753 & 0.999 & IRS & $1998-99$ & 0.976 & 0.985 & 1.000 & 0.991 & DRS \\
\hline
\end{tabular}


Vijayamohanan Pillai N., AM Narayanan; Measuring Energy Efficiency in Kerala: Data Envelopment Analysis, Journal of Biomedical Engineering and Medical Imaging, Volume 6, No 4, Aug (2019) , pp 16-28

\begin{tabular}{|l|l|l|l|l|l|l|l|l|l|l|l|}
\hline $1975-76$ & 0.769 & 0.769 & 0.775 & 1.000 & CRS & $1999-00$ & 0.968 & 0.977 & 0.986 & 0.991 & DRS \\
\hline $1976-77$ & 0.881 & 0.882 & 0.881 & 1.000 & IRS & $2000-01$ & 0.969 & 0.978 & 0.989 & 0.991 & DRS \\
\hline $1977-78$ & 0.973 & 0.973 & 0.973 & 1.000 & IRS & $2001-02$ & 0.944 & 0.953 & 0.963 & 0.991 & DRS \\
\hline $1978-79$ & 1.000 & 1.000 & 1.000 & 1.000 & CRS & $2002-03$ & 0.953 & 0.962 & 0.972 & 0.990 & DRS \\
\hline $1979-80$ & 0.991 & 0.991 & 0.995 & 1.000 & IRS & $2003-04$ & 0.952 & 0.962 & 0.976 & 0.990 & DRS \\
\hline $1980-81$ & 0.975 & 0.976 & 0.982 & 0.999 & IRS & $2004-05$ & 0.941 & 0.951 & 0.960 & 0.990 & DRS \\
\hline $1981-82$ & 0.986 & 0.988 & 1.000 & 0.999 & DRS & $2005-06$ & 0.958 & 0.968 & 0.977 & 0.990 & DRS \\
\hline $1982-83$ & 0.918 & 0.920 & 0.933 & 0.998 & IRS & $2006-07$ & 0.968 & 0.978 & 0.986 & 0.989 & DRS \\
\hline $1983-84$ & 0.882 & 0.884 & 0.901 & 0.998 & IRS & $2007-08$ & 0.973 & 0.984 & 0.988 & 0.989 & DRS \\
\hline $1984-85$ & 0.876 & 0.878 & 0.893 & 0.998 & IRS & $2008-09$ & 0.964 & 0.975 & 0.978 & 0.989 & DRS \\
\hline $1985-86$ & 0.893 & 0.895 & 0.919 & 0.998 & IRS & $2009-10$ & 0.965 & 0.976 & 0.978 & 0.989 & DRS \\
\hline $1986-87$ & 0.903 & 0.905 & 0.934 & 0.998 & IRS & $2010-11$ & 0.968 & 0.979 & 0.981 & 0.989 & DRS \\
\hline $1987-88$ & 0.906 & 0.908 & 0.938 & 0.997 & IRS & $2011-12$ & 0.976 & 0.988 & 0.990 & 0.989 & DRS \\
\hline $1988-89$ & 0.924 & 0.927 & 0.961 & 0.997 & IRS & $2012-13$ & 0.977 & 0.988 & 0.988 & 0.989 & DRS \\
\hline $1989-90$ & 0.912 & 0.915 & 0.947 & 0.997 & IRS & $2013-14$ & 0.988 & 1.000 & 1.000 & 0.988 & DRS \\
\hline $1990-91$ & 0.941 & 0.945 & 0.980 & 0.996 & IRS & $2014-15$ & 0.984 & 0.996 & 0.996 & 0.988 & DRS \\
\hline $1991-92$ & 0.948 & 0.952 & 1.000 & 0.996 & IRS & $2015-16$ & 0.986 & 0.999 & 0.999 & 0.987 & DRS \\
\hline $1992-93$ & 0.959 & 0.963 & 1.000 & 0.996 & DRS & $2016-17$ & 0.986 & 1.000 & 1.000 & 0.986 & DRS \\
\hline $1993-94$ & 0.935 & 0.942 & 0.954 & 0.993 & DRS & & & & & & \\
\hline
\end{tabular}

Note: CRS = Constant returns to scale; VRS = Variable returns to scale; NIRS = Non-increasing returns to scale; DRS = decreasing returns to scale; RTS = Returns to scale; Scale = Scale efficiency.

The tertiary sector comes second to the secondary sector in terms of efficiency performance, being close to the frontier for a few years (Table 3). In scale efficiency, the same pattern as in the secondary sector holds here, the fall into DRS, however, starting from the early 1990s. 

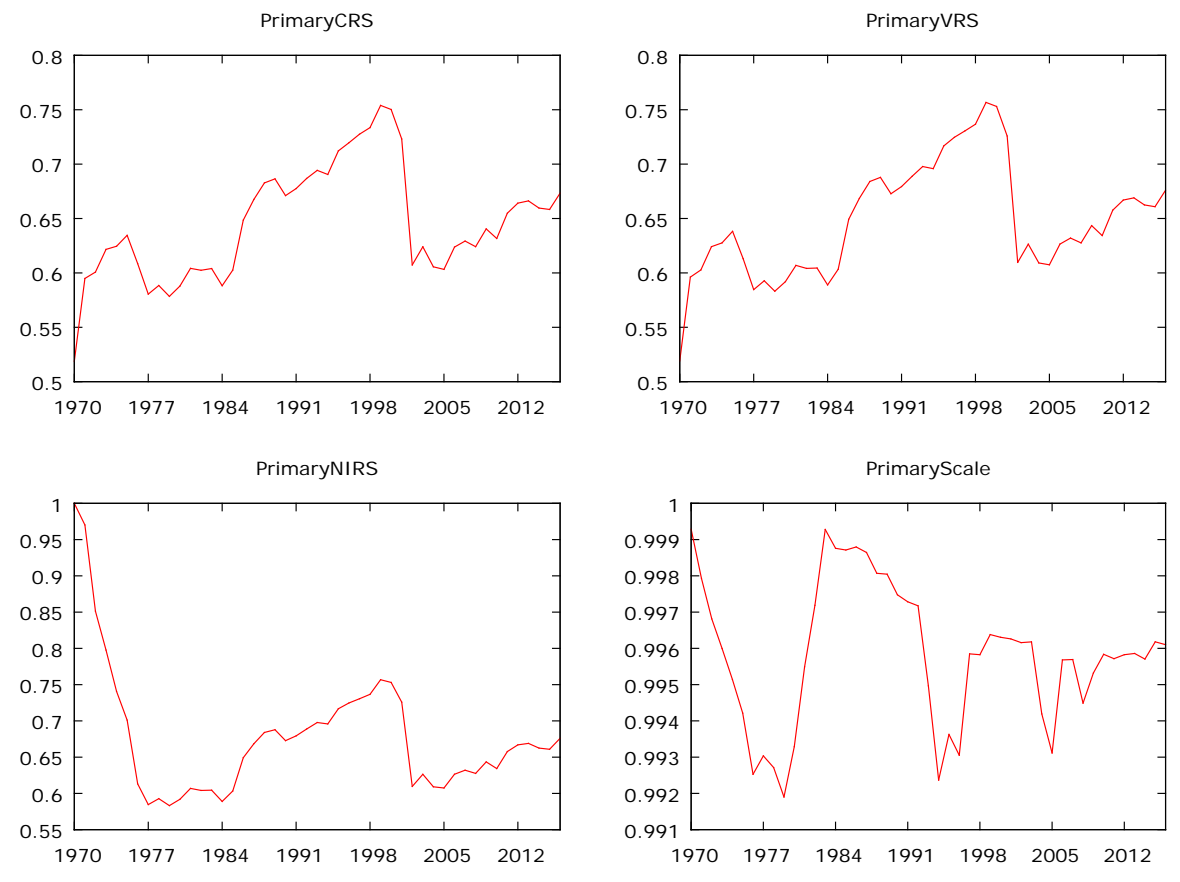

Figure. 2: DEA Efficiency Estimates - Primary Sector- Model-wise
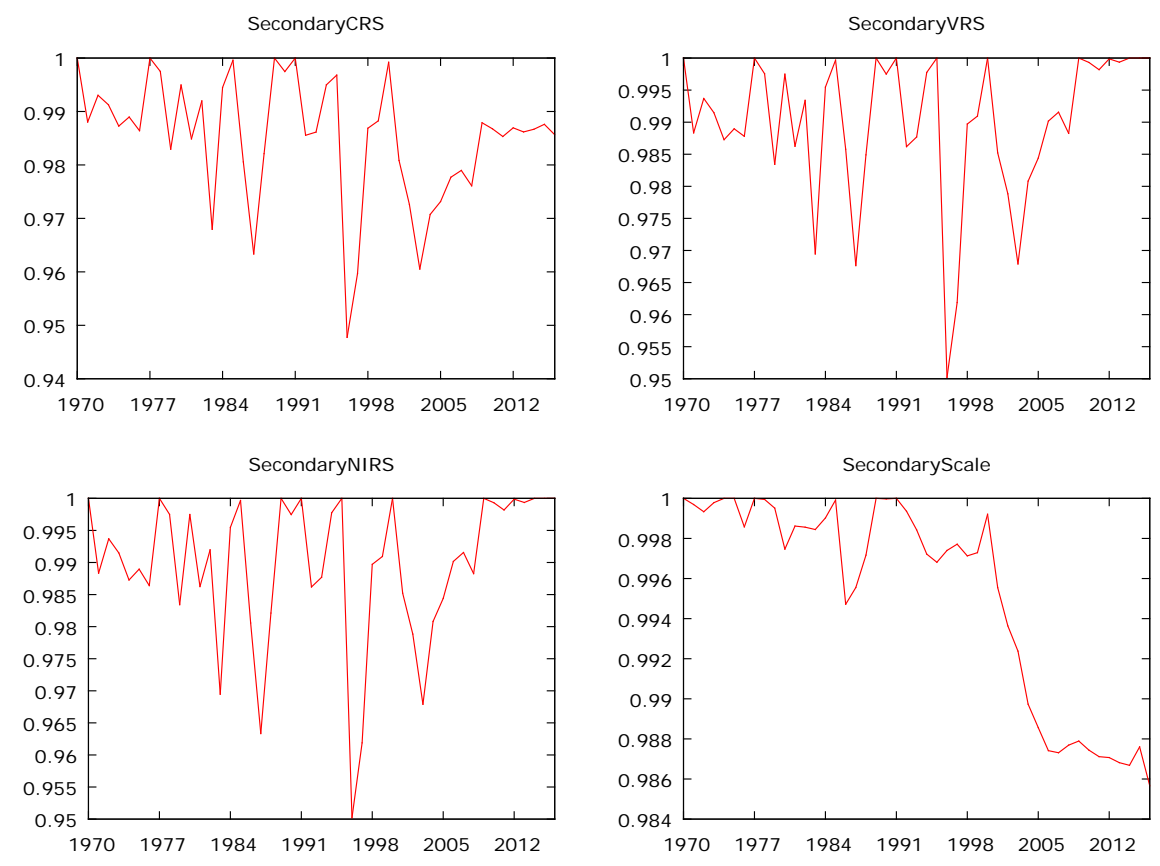

Figure. 3: DEA Efficiency Estimates - Secondary Sector- Model-wise 
Vijayamohanan Pillai N., AM Narayanan; Measuring Energy Efficiency in Kerala: Data Envelopment Analysis, Journal of Biomedical Engineering and Medical Imaging, Volume 6, No 4, Aug (2019) , pp 16-28
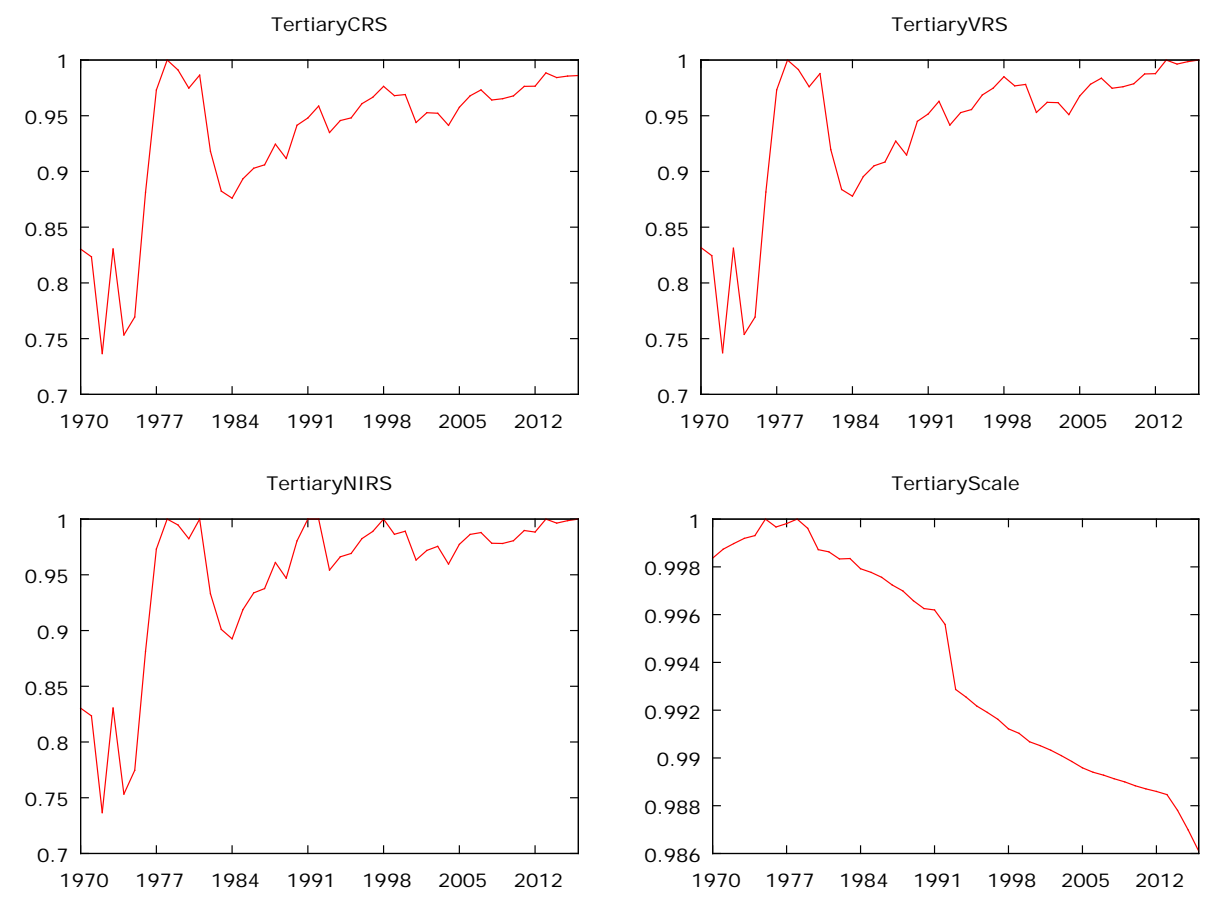

Figure. 4: DEA Efficiency Estimates - Tertiary Sector- Model-wise

Table 4: DEA Efficiency Estimates - Summary Statistics

\begin{tabular}{|l|l|l|l|l|l|l|l|l|l|l|l|}
\hline Variable & Mean & Median & Minimum & Maximum & $\begin{array}{l}\text { Std. } \\
\text { Dev. }\end{array}$ & C.V. & Skewness & $\begin{array}{l}\text { Excess } \\
\text { kurtosis }\end{array}$ & $\begin{array}{l}5 \% \\
\text { Perc. }\end{array}$ & $\begin{array}{l}95 \% \\
\text { Perc. }\end{array}$ & $\begin{array}{l}\text { IQ } \\
\text { range }\end{array}$ \\
\hline Primary CRS & 0.645 & 0.635 & 0.519 & 0.754 & 0.052 & 0.080 & 0.221 & -0.368 & 0.579 & 0.744 & 0.079 \\
\hline Primary VRS & 0.648 & 0.638 & 0.519 & 0.757 & 0.052 & 0.080 & 0.218 & -0.329 & 0.584 & 0.746 & 0.077 \\
\hline Primary NIRS & 0.679 & 0.667 & 0.583 & 1 & 0.088 & 0.130 & 1.881 & 4.171 & 0.586 & 0.923 & 0.107 \\
\hline Primary Scale & 0.996 & 0.996 & 0.992 & 0.999 & 0.002 & 0.002 & -0.153 & -0.638 & 0.992 & 0.999 & 0.003 \\
\hline Secondary CRS & 0.985 & 0.987 & 0.948 & 1 & 0.012 & 0.012 & -1.065 & 1.076 & 0.960 & 1 & 0.014 \\
\hline Secondary VRS & 0.990 & 0.991 & 0.950 & 1 & 0.011 & 0.011 & -1.521 & 2.289 & 0.964 & 1 & 0.014 \\
\hline $\begin{array}{l}\text { Secondary } \\
\text { NIRS }\end{array}$ & 0.990 & 0.991 & 0.950 & 1 & 0.012 & 0.012 & -1.449 & 1.927 & 0.962 & 1 & 0.014 \\
\hline $\begin{array}{l}\text { Secondary } \\
\text { Scale }\end{array}$ & 0.995 & 0.997 & 0.986 & 1 & 0.005 & 0.005 & -0.740 & -1.151 & 0.987 & 1 \\
\hline Tertiary CRS & 0.931 & 0.953 & 0.737 & 1 & 0.064 & 0.069 & -1.584 & 1.824 & 0.760 & 0.990 & 0.067 \\
\hline Tertiary VRS & 0.937 & 0.962 & 0.737 & 1 & 0.067 & 0.071 & -1.538 & 1.624 & 0.760 & 1 \\
\hline Tertiary NIRS & 0.948 & 0.977 & 0.737 & 1 & 0.068 & 0.072 & -1.772 & 2.186 & 0.762 & 1 \\
\hline Tertiary Scale & 0.994 & 0.993 & 0.986 & 1 & 0.004 & 0.005 & -0.060 & -1.590 & 0.987 & 0.9999 & 0.009 \\
\hline
\end{tabular}

Note: $\mathrm{CRS}=$ Constant returns to scale; VRS = Variable returns to scale; NIRS = Non-increasing returns to scale; Std.

Dev = Standard Deviation; C.V. = Coefficient of Variation; Perc = Percentile; IQ = Inter-Quartile. 


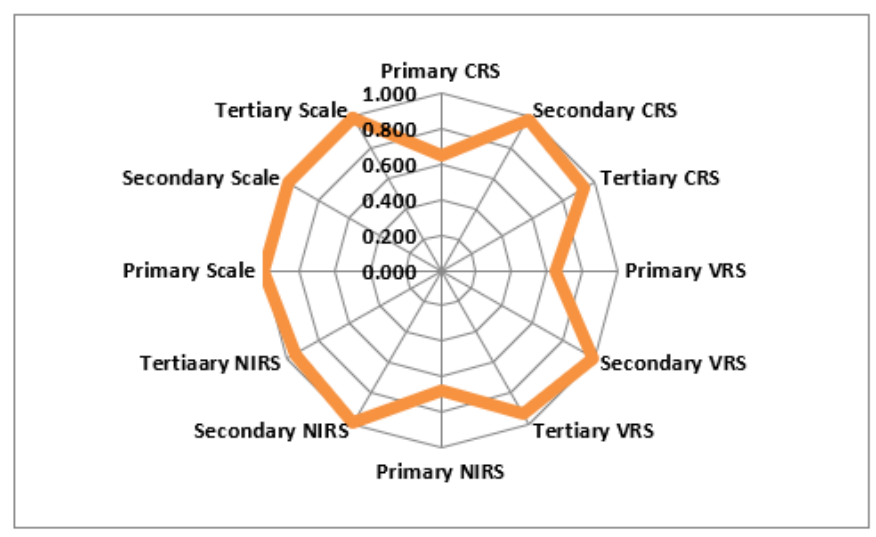

Figure. 5: Mean DEA Efficiency Estimates - Sector- and Model-wise

Note: $\mathrm{CRS}=$ Constant returns to scale; VRS = Variable returns to scale; NIRS = Non-increasing returns to scale;

\section{Conclusion}

In this paper we have taken up the non-parametric mathematical programming method of data envelopment analysis, the second approach in multi-factor productivity analysis. We have started with the theoretical framework of data envelopment analysis (DEA) as a prelude to our empirical exercise for the Kerala power sector. This approach originated with Farrell who decomposed the concept of economic efficiency (overall efficiency) of a production unit into two components, viz., technical efficiency and allocative efficiency (price efficiency); for illustrating this approach, he used the usual economic concepts of isoquant and price line (isocost line) involving a production function of two inputs and one output under the assumption of constant returns to scale.

In this context, for measuring the unknown efficiency of a production unit in relation to an efficient isoquant (representing an efficient firm) using the sample data, Farrell suggested (i) a non-parametric piecewise-linear convex isoquant, or (ii) a parametric frontier function, such as the Cobb-Douglas production function. The second of these we have employed in the last chapter, and the first one in this chapter.

The non-parametric linear programming data envelopment analysis (DEA) was proposed by Charnes, Cooper and Rhodes (1978), which paved the way for a large number of papers in applications and extensions. DEA model has two variants, one under the assumption of constant returns to scale (CRS), and the other under variable returns to scale (VRS) assumption. One advantage of this approach is that it can be used for multiple output-multiple input cases, unlike in the parametric production function analysis.

Following the theoretical framework, we have turned to estimating the DEA frontier of the power sector in Kerala, considering three sectors (Primary, Secondary and Tertiary) for the period from 1970-71 to 2016-17. We have used the sectoral energy consumption as a function of sectoral number of consumers and sectoral GSDP at constant 2011-12 prices (all variables taken in log), unlike the usual frontier function with factors of production, to represent frontier isoquant with two activity factors and one output. For estimating our DEA, we have made use of a Stata module for DEA, provided by Chonjoo Lee and Ji Yong-Bae (2009).

We have estimated the efficiency measures for the three sectors under the two scale assumptions of constant returns to scale (CRS) and variable returns to scale (VRS); the latter includes both increasing (IRS) and decreasing 
Vijayamohanan Pillai N., AM Narayanan; Measuring Energy Efficiency in Kerala: Data Envelopment Analysis, Journal of Biomedical Engineering and Medical Imaging, Volume 6, No 4, Aug (2019) , pp 16-28

returns to scale (DRS). Scale efficiency measures are also given to find out whether a firm is operating at its optimal size or not, implying degrees of capacity utilization.

The results have shown that energy efficiency in the primary sector is much lower than in the other two sectors; the scale efficiency is below, but close to, optimum. Surprisingly, the primary sector during the entire period is found to be in IRS stage. The secondary sector is found to have the highest energy efficiency scores for all the years, its performance in a number of years being on or very close to the frontier; the scale efficiency also faring similarly. Coming to the returns to scale, the sector mostly experienced IRS or CRS in the initial years, whereas from the late 1990s the sector fell in the stage of DRS. The tertiary sector follows the secondary sector in terms of efficiency performance, being close to the frontier for a few years. After the initial years of mostly IRS, the sector fell into DRS, starting from the early 1990s.

\section{REFERENCES}

[1] Afriat, S.N. (1972), "Efficiency Estimation of Production Functions", International Economic Review, 13, 568-598.

[2] Ang, B.W., (2004). 'Decomposition analysis for policymaking in energy: which is the preferred method?', Energy Policy, 32, pp. 1131-1139.

[3] Ang B.W. and K.H. Choi (1997). "Decomposition of aggregate energy and gas emission intensities for industry: a refined Divisia index method". The Energy Journal. 18(3): 59-73.

[4] Ang B.W., F.Q. Zhang and K.H. Choi (1998)."Factorizing changes in energy and environmental studies through decomposition". Energy 23(6): 489-495.

[5] Ang B.W. and F.Q. Zhang (2000). "A survey of index decomposition analysis in energyand environmental studies". Energy 25(12):1149-1176.

[6] anker, R.D., A. Chames and W.W. Cooper (1984), "Some Models for Estimating Technical and Scale Inefficiencies in Data Envelopment Analysis", Management Science, 30, 1078-1092.

[7] Boles, J.N. (1966), "Efficiency Squared - Efficient Computation of Efficiency Proceedings of the 39th Annual Meeting of the Western Farm Economic Association, pp 137-142.

[8] Bossanyi, E. (1979). UK primary energy consumption and the changing structure of final demand. Energy Policy 7(6): 489-495

[9] Boyd, Gale; McDonald, John; Ross, M. and Hansont, D. A. (1987) "Separating the Changing Composition of U.S. Manufacturing Production from Energy Efficiency Improvements: A Divisia Index Approach". The Energy Journal, Volume 8, issue Number 2, 77-96

[10] Charnes, A., W.W. Cooper and E. Rhodes (1978), "Measuring the Efficiency of Decision Making Units", European Journal of Operational Research, 2, 429-444.

[11] Coelli, T.J., Rao D.S.P., O’Donnell C.J. and Battese G.E. (2005). An introduction to efficiency and productivity analysis. Springer 
Journal of Biomedical Engineering and Medical Imaging, Volume 6, No 4, August 2019

[12] Cooper, W.W., Seiford L.M. and Tone K. (2006). Introduction to Data Envelopment Analysis and its uses. Springer.

[13] Farrell, M.J. (1957), "The Measurement of Productive Efficiency", Journal of the Royal Statistical Society, Series A, CXX, Part 3, 253-290.

[14] Henderson, James M. and Quandt, Richard E. (1971) Microeconomic Theory: A Mathematical Approach. 2nd edition. McGraw-Hill Kogakusha, London.

[15] Myers, J. and Nakamura L. (1978). Saving energy in manufacturing. Cambridge, MA: Ballinger, 1978.

[16] Patterson, Murray G (1996) "What is energy efficiency? Concepts, indicators and methodological issues". Energy Policy, vol. 24, issue 5, 377-390.

[17] Yong-bae Ji and Choonjoo Lee, (2010). “Data Envelopment Analysis in Stata”. The Stata Journal Vol. 10: 2, pp. 267280. 